\title{
Factors related to girls' choice of physics for university entrance exams in Japan
}

\author{
Yuko Ikkatai@, ${ }^{1}$ Atsushi Inoue $\odot,{ }^{2}$ Kei Kano $\odot,{ }^{3}$ Azusa Minamizaki®, ${ }^{4}$ \\ Euan McKay๑,$^{5}$ and Hiromi M. Yokoyama® $\oplus^{1, *}$ \\ ${ }^{1}$ Kavli Institute for the Physics and Mathematics of the Universe, The University of Tokyo, \\ 5-1-5 Kashiwanoha, Kashiwa, Chiba 277-8583, Japan \\ ${ }^{2}$ Nippon Institute for Research Advancement, \\ Yebisu Garden Place Tower, 34th Floor 4-20-3 Ebisu, Shibuya-ku, Tokyo 150-6034, Japan \\ ${ }^{3}$ Graduate School of Education, Shiga University, 2-5-1 Hiratsu, Otsu, Shiga 520-0862, Japan \\ ${ }^{4}$ Kobayashi-Maskawa Institute for the Origin of Particles and the Universe, Nagoya University, \\ Furo-cho, Chikusa-ku, Nagoya, Aichi 464-8602, Japan \\ ${ }^{5}$ Division for Strategic Public Relations, The University of Tokyo, \\ 7-3-1, Hongo, Bunkyo-ku, Tokyo 113-0033, Japan
}

(Received 19 October 2020; accepted 29 April 2021; published 21 June 2021)

\begin{abstract}
Women are underrepresented in physics. Because of the structure of the Japanese educational system, more women must choose physics as a subject for university entrance exams to increase the number of women studying advanced physics at university. In this study, we investigated the factors influencing girls' choice of physics for university entrance examination in Japan, focusing on preference and selfefficacy for science subjects. We investigated two Japanese populations (members of the public who graduated from university with a degree in science, and professional physicists) to identify characteristics of physicists. We conducted online retrospective questionnaires. First, we found that the preference for physics at junior high school and the first year of high school were positively related to the choice of physics for university entrance exams in both female and male university science graduates. Second, we found that preferences for museums and science magazines as well as the recognition of the importance of physics and mathematics at elementary or junior high school were significantly related to the choice of physics for female university science graduates. Third, we found that professional physicists, especially women, had a lower mathematical stereotype than male and female university science graduates. Our results suggest that initiatives to prevent girls from disliking physics at junior high school or high school may be important for encouraging them to choose physics for university entrance examination in Japan.
\end{abstract}

DOI: 10.1103/PhysRevPhysEducRes.17.010141

\section{INTRODUCTION}

\section{A. Japanese women in physics}

In Japan, women are particularly underrepresented in physics departments. The percentage of female students in physics at universities was $15.4 \%$ for undergraduates in 2018 [1]. Some initiatives to encourage junior high and high school girls to choose science, technology, engineering, and mathematics (STEM) subjects have been

\footnotetext{
*Corresponding author. hiromi.yokoyama@ipmu.jp

Published by the American Physical Society under the terms of the Creative Commons Attribution 4.0 International license. Further distribution of this work must maintain attribution to the author(s) and the published article's title, journal citation, and DOI.
}

conducted. For example, the Gender Equality Bureau Cabinet Office, an organization in the government of Japan has conducted an initiative called the Rikó-challenge ${ }^{1}$ (e.g., Ref. [2]). The Riko-challenge introduces universities and companies that are active in STEM and provide information on STEM for girls in junior high and high schools. But there are still few girls studying physics at university. The factors discouraging girls from studying physics are still the subjects of study in Japan.

Japanese students take "science" as part of their compulsory education at elementary and junior high school. Science is generally provided and includes a range of subjects. In the National Assessment of Academic Ability in 2018, the percentage of Japanese students who say they like science decreased from elementary school $(83.5 \%)$ to

${ }^{1}$ Riko means science and engineering in Japanese. 
TABLE I. Five factors.

\begin{tabular}{|c|c|c|c|c|}
\hline Factor & Label in this study & Cheryan et al. [12] & Ikkatai et al. [13] & Harada et al. [4] \\
\hline 1 & Mathematical stereotype & Masculine culture of the fields & Masculine culture of the fields & \\
\hline 2 & Activities and memories in childhood & Insufficient early experience & Insufficient early experience & \\
\hline 3 & Self-efficacy for science subjects & Gender gaps in self-efficacy & Gender gaps in self-efficacy & Control belief \\
\hline 4 & Preference for science subjects & & & Interest value \\
\hline 5 & Egalitarian attitude toward gender roles & & $\begin{array}{c}\text { Social climate of surrounding } \\
\text { gender roles }\end{array}$ & \\
\hline
\end{tabular}

junior high school (62.9\%) [3]. ${ }^{2}$ Additionally, junior high school girls tend to significantly lose interest in science between the first and second year [4]. This shows that junior high school is an important time to encourage girls to study physics.

At high school, students get to choose which science subject they study. In the current education guidelines, released in 2012 [5], students must choose three science classes among the four basic classes ("basic physics," "basic chemistry," "basic biology," "basic earth science"), or two classes ("Science and our daily life", plus one basic science class). Advanced science classes ("physics," "chemistry," "biology," and "earth science") can be chosen after students finish the corresponding basic subjects. In many high schools in Japan, students need to choose science or humanities courses at the second year. If students choose humanities courses, they have fewer opportunities to take physics classes at high school. Of all female highschool students the percentage taking physics is not officially announced, but we estimate it to be about $4 \%{ }^{4}$

Japanese students need to take an entrance examination to enter university. The pattern of the examination subjects varies depending on the departments and faculties of the universities. Science departments and faculties generally ask students to take science exams prepared by the university. It would be hard for students to study almost all of the advanced physics and engineering courses at

\footnotetext{
${ }^{2}$ The National Assessment of Academic Ability is a survey conducted by the Ministry of Education, Culture, Sports, Science and Technology (MEXT). The survey is conducted every year in April for sixth graders and ninth graders in Japan, and examines their academic performance and learning status up to the previous year. For science, the survey has been conducted once every three years since 2012 .

${ }^{3}$ The class "Science and our daily life" aims to learn about how the understanding of nature and the development of science and technology have influenced our daily lives and society, and what role they have played. This is a very foundational subject among all the science subjects and has nothing to do with university entrance exam subjects.

${ }^{4}$ One report stated that the percentage of students who chose the advanced physics class (Physics II) was about 20\% from 2005 to 2011 [6]. Another report showed that the percentage of the advanced physics class (Physics II) being chosen was $80 \%$ boys and 20\% girls [7]. Therefore, we can assume that the percentage of high school girls who choose the advanced physics class (Physics II) is $4 \%$.
}

university without having studied physics at high school. The percentages of third-year high school students in science courses who take the basic physics class (Physics I in the previous guideline) for the national center test for university admissions among each population are $69 \%$ boys and $30 \%$ girls among applicants for university or junior college. Furthermore, the percentage of those who take the advanced physics class (Physics II) for university entrance exams among each population was 55\% boys and 20\% girls [8]. These numbers show that girls are less likely to choose physics for university entrance examinations. This means that to increase the number of women in advanced physics, it is necessary under the Japanese educational system to increase the number of women choosing physics in high school to increase the number of university entrance examinations; encouraging girls to study physics at junior high schools before high schools is also important.

The percentage of female students in physics departments at universities is $15.4 \%$ for undergraduates, $11.0 \%$ in master's courses, and $11.3 \%$ in doctoral courses in 2018 [1]. Furthermore, there are fewer female professional physicists than men. Only 6\% $(n=981)$ of the members of the Physical Society of Japan (JPS) are women. The JPS is an organization of physicists that had 16544 members in 2007 [9]. Since 2011, the percentage of new female members has remained constant at less than 10\% [10].

\section{B. Five candidate factors influencing girls' choice of physics}

Identifying factors that encourage girls to study physics is important not only to enhance girls' choice of physics as a subject for university entrance exams in Japan but also to fill the gender gap in physics. A study indicated that most of the gender gap in the performance in physics at university can be explained by nongender factors [11].

There could be many factors, but in this study we focused on five factors based on a framework from three studies (Table I). First, Cheryan et al. proposed a model to explain the lower representation of women in computer science, engineering, and physics less than biology, chemistry, and mathematics in the US [12]. This model includes three factors: masculine culture of the fields, insufficient early experience, and gender gaps in self-efficacy. Second, Ikkatai et al. [13] propose a model explaining Japanese 
public masculine image of physics, which added the fourth factor of social climate of surrounding gender role in addition to the Cheryan et al.'s model. However, these two studies do not focus exclusively on junior high school students. We then used a study of Harada et al. that examined the level of control belief and interest value of junior high school students in Japan [4].

We have integrated these factors the studies focused $[4,12,13]$ into five factors. The first factor was "mathematical stereotype," which is related to the "masculine culture of the fields" (more specifically "negative stereotypes of women's' abilities") in the model of Cheryan et al. [12]. Math stereotypes are negative stereotypes that women are not as good at mathematics as men. Studies have shown that math stereotypes make girls stay away from STEM. Girls choose physical sciences over nonscience fields only when their mothers have a strong belief in their daughters' mathematics performance [14]. A psychological experiment suggests that Japanese girls' motivation to study mathematics was changed by oral comments. When girls got good scores on mathematics exams, their motivations were lower when they were told, "Good job even though you're a girl" rather than "Good job" [15]. Because mathematics is essential for physics, Japanese girls who have strong a mathematical stereotypic belief might shy away not only from mathematics but also from physics.

The second factor was "activities and memories in childhood." This is related to "insufficient early experience" in Cheryan et al.'s model (more specifically "gender gaps in early educational experience"), although this was eventually ruled out from the model [12]. We focus on this as a previous survey showed that some science-related experiences in childhood are biased toward girls or boys in Japan [16]. For example, "I care for animals and plants" and "I went to museums" were chosen more often by girls. "I liked science experiments" and "I was interested in mechanics and manufacturing" were chosen more often by boys. A survey of second-year junior high school students in 2018 reported that girls who went to science museums tended to be good at science subjects [17]. In another survey of the Japanese public aged from 18 to 69 , women who wanted to be scientists or engineers tended to study science subjects. These findings suggest that some experiences entice girls to choose STEM fields, but it has not been examined which experiences are specifically related to the choice of physics.

The third factor was "self-efficacy for science subjects," which is related to "gender gaps in self-efficacy" of Cheryan et al.'s model [12]. In Japan, Harada et al. showed that there were significant differences between boys and girls for their control beliefs ${ }^{5}$ in two units ("electric currents" and "electric currents and magnetic") that they

\footnotetext{
${ }^{5}$ The students answered the item "I think I can get a good grade if I try to get a good grade by studying [the unit name] by fivepoint scales from totally disagree to totally disagree.
}

learn in their second year of junior high school. Boys showed positive control beliefs that they could get good scores, but girls did not. This gender difference was not found for other units such as "chemical change and mass change," "organisms and cell," and "weather changes" [4]. We considered that Japanese girls with a low self-efficacy for physics at junior high school may turn away from choosing physics.

The fourth factor was "preference for science subjects." Both girls and boys start to lose interest in science at the first year of junior high school in Japan. ${ }^{6}$ Boys do not tend to show a clear reduction in their like or dislikes of science after the second year, but girls show a significant reduction between the first year and second year. Harada et al. concluded that both control belief and interest value affect their like or dislike of science [4].

The fifth factor is "egalitarian attitude toward gender roles." It has been reported that women's gender role beliefs are related to their future occupations in the UK. Women who had traditional gender role beliefs in adolescence were significantly less likely to be employed in physical sciences, mathematics, engineering, and technology-related careers [18]. Japan is a country with a large gender gap. Japan's ranking in the Global Gender Gap Index-higher rankings show gender-equal countries-was 121st among 153 countries in 2019 [19]. Japanese parents with a low level of egalitarian attitude have a negative attitude toward girls studying at universities, including physics [20]. People who have a low level of gender role beliefs may shy away from physics. Egalitarian attitudes toward gender roles was not significantly related to the masculine image of physics in Japan [13]. But we still included this factor considering the current situation of lower gender equality in Japan.

\section{Research questions}

The uniqueness of this study is that we focused on the Japanese education system and the choice of physics as a subject for university entrance examinations. We conducted online retrospective questionnaires for two groups to investigate which factors enabled them to choose physics. The first group was the general public who have graduated from science-related departments at universities (university science graduates) but are not professional physicists. The second population group was professional physicists.

The research questions were as follows:

- RQ1: How were the preference and self-efficacy for science subjects related to the choice of physics for university entrance exams (for the group who graduated with science degrees)?

- RQ2: What kinds of childhood activities or memories were related to the preference for physics at junior high school (for the group who graduated with science degrees)?

\footnotetext{
${ }^{6}$ The students answered the item "Do you like science subjects?" by five-point scales from very like to very dislike.
} 
TABLE II. Demographic information showing age, gender, and educational attainment of respondents.

\begin{tabular}{|c|c|c|c|c|c|c|c|c|}
\hline & \multicolumn{4}{|c|}{ University science graduates } & \multicolumn{4}{|c|}{ Professional physicists } \\
\hline & \multicolumn{2}{|c|}{$\operatorname{Men}(n=547)$} & \multicolumn{2}{|c|}{ Women $(n=554)$} & \multicolumn{2}{|c|}{ Men $(n=419)$} & \multicolumn{2}{|c|}{ Women $(n=71)$} \\
\hline Age $($ mean $\pm \mathrm{SD})$ & \multicolumn{2}{|c|}{$50.6 \pm 13.9$} & \multicolumn{2}{|c|}{$50.4 \pm 13.7$} & \multicolumn{2}{|c|}{$42.6 \pm 12.0$} & \multicolumn{2}{|c|}{$37.2 \pm 12.6$} \\
\hline Educational attainment & $n$ & $\%$ & $n$ & $\%$ & $n$ & $\%$ & $N$ & $\%$ \\
\hline Bachelor's & 418 & 76.4 & 487 & 87.9 & 15 & 3.6 & 8 & 11.3 \\
\hline Master's & 108 & 19.7 & 49 & 8.8 & 49 & 11.7 & 15 & 21.1 \\
\hline Doctoral & 21 & 3.8 & 18 & 3.2 & 350 & 83.5 & 47 & 66.2 \\
\hline Others & NA & NA & NA & NA & 5 & 1.2 & 1 & 1.4 \\
\hline
\end{tabular}

Note that NA means "not available."

- RQ3: What were the differences found between the group who graduated with science degrees and professional physicists in terms of their preference and self-efficacy for physics, their mathematical stereotype, and their egalitarian attitude for gender role?

\section{METHODOLOGY}

\section{A. Respondents}

\section{University science graduates}

We collected responses from 1101 (women $=554$, men $=547$ ) members of the public who live in Japan, aged from 20 to 69 . The respondents were limited to those who graduated from science-related departments or faculties at universities: physical sciences; engineering; agricultural science; health in S_Table 1 of the Supplemental Material [21]. These departments or faculties were determined based on the categories of departments or faculties used in a survey by Gakkō Kihon Chōsa [22] and the Japan Doctoral Human Resource Profiling [23]. We targeted this group because they would likely have been encouraged, for their futures, to choose physics at high school. The probability of choosing physics at high school would be higher in students who are taking science courses compared with those who are taking humanities courses.

Our samples matched the current demographic profile of the Japanese population for gender (men, women), age, and region. The authors employed NTTCom Online Marketing Solutions Corporation, a research company in Japan, to collect the data online using the company's data pool. The company sent an email to registrants who met our criteria requesting their participation. As the company did not have a data pool whose gender identity was "other," we limited the responses to those whose gender identity was "male" or "female." Data collection was stopped soon after the number of responses reached the predefined number of responses $(n=1000)$. This survey was conducted from March 22 to 25, 2019.

\section{Professional physicists}

We collected responses from professional physicists in Japan. In this paper, we operationally defined a "professional physicist" as a person who is a member of the JPS, an organization of physicists founded 1877 in Japan [24]. They were chosen because they were the extreme cases who pursued physics.

To collect their responses, we asked for the cooperation for the Gender Equality Promotion Committee of the JPS. We asked JPS to send the link for the online retrospective questionnaire to subareas on their mailing list. There were 15,981 JPS members in March 2019 (personal communication, January 22, 2020), but the number of registered members has not officially announced. In 2007, only $6 \%$ were female JPS members [9]. Data collection was conducted from May 15 to 29, 2019. We collected responses from 495 members $($ women $=71$, men $=423$, other $=1$ ) aged from 21 to 81 .

We removed five responses to match data conditions from the public: one was from a respondent whose gender identity was "other" ( $n=1)$ and four were from the respondents who graduated from "technical college $(n=4)$." In total, 490 responses $($ women $=71$, men $=419$ ) were used for analysis.

\section{B. Questionnaire items}

We conducted online retrospective questionnaires for members of the public who graduated with a science degree (university science graduates) and, separately, for professional physicists. We reported only the following items, although the questionnaire included many more.

- Demographic information. Age, gender, educational attainments (Table II) and occupation were included. The top three occupations with the most responses were full-time company employee $(36.6 \%, n=403)$, housewife or husband $(17.3 \%, n=191)$, and unemployed $(14.4 \%, n=158)^{7}$ in university science graduates, and research position in national or private

\footnotetext{
${ }^{7}$ We collected the data from those aged from 20 to 69 , but many Japanese companies or institutions have a mandatory retirement age of 65 . About half of our sample who are unemployed were aged over 65 years old $(n=82)$. It is thus the unemployment rate between 20 and 64 in our sample was $8.4 \%(n=76)$. However, this is still higher than actual general unemployment rate $(2.4 \%)$ for 15 to 64 years old in 2019 [25].
} 
university $(55.9 \%, n=274)$, research position in national or private research institute $(20.8 \%$, $n=102)$, and graduate student $(13.1 \%, n=64)$ in professional physicists.

- Pattern of the choice of science subjects for university entrance exams. We asked the respondents to choose all science subjects (physics, chemistry, biology, earth science, mathematics, none of the above, others) that they used for university entrance exams. We categorized their patterns into five levels: (a) one physics subject, (b) one subject other than physics, (c) more than two subjects including physics, (d) more than two subjects other than physics, (e) others. Further, we categorized the patterns into two levels for regression analysis: selected physics $[(\mathrm{a})+(\mathrm{c})]$ and unselected physics $[(\mathrm{b})+(\mathrm{d})+(\mathrm{e})]$.

- Mathematical stereotype. We asked the respondents to answer how much they agreed with the statement "women are not as good at mathematics as men." Their responses were rated on a five-point Likert scale (strongly agree $=1$, agree $=2$, neither agree not disagree $=3$, disagree $=4$, strongly disagree $=5$ ). The higher scores meant that the respondents had a weaker mathematical stereotype.

- Activities and memories in childhood. We asked the respondents to choose all that applied from 28 items at elementary school, 31 items at junior high school, and 31 items at high school in S_Table 2 and S_Table 3 of the Supplemental Material [21]. For elementary school, 18 out of the 28 items were chosen based on a previous survey [26]. We added 10 new items relating to STEM: handicrafts (Q1-13), math (Q1-14), chemical experience (Q1-15), physics, mathematics, and biology Olympics (Q1-16 to Q1-18), computers (Q1-22), and learning science and math (Q1-26, Q127). We further added items about physics, biology, earth science, chemistry, mathematics (Q2-26 to Q230), and high school (Q3-26 to Q2-30). We added the item "other" for professional physicists but not for the public. We later excluded "other" from our analysis.

- Self-efficacy for science subjects. We asked the respondents to choose how well they performed for mathematics and science at elementary school and mathematics, physics, chemistry, biology, and earth science at junior high school, and separately during the first and second year of high school. Their responses were rated on "I can't perform," "I probably can't perform," "I probably can perform," "I can perform," or "unselected." We categorized their responses into three levels: "low" (including I can't perform, probably I can't perform and unselected), and "relatively high" (= probably I can perform) and "high" (= I can perform) for regression analysis.

- Preference for science subjects. We asked the respondents to choose how much they preferred mathematics and science at elementary school as well as mathematics, physics, chemistry, biology, and earth science at junior high school, and the first year and second year of high school. Two grades (first and second year) at high school were answered separately, as the course selection between the humanities or science is often done before the start of the second year. Their responses were rated on "dislike," "probably dislike," "probably like," "like," or "unselected." We categorized their response into three levels: "low" (including dislike, probably dislike, and unselected), "relatively high" (= probably like) and "high" (= like) for regression analysis.

- Egalitarian attitude toward gender roles. We measured the individual egalitarian gender role attitude using the Japanese version of the short form of the Scale of Egalitarian Sex Role Attitudes (SESRA-S, [27-29]). SESRA-S has 15 items (four non-reversed items and 11 reversed items) ${ }^{8}$ in three categories: marriage (e.g., domestic chores should be shared between spouses, reversed item); parenting (e.g., daughters should be raised to become housewives and sons to have jobs, reversed item); and working (e.g., women should work even after having a child, nonreversed). Each answer was rated on a five-point Likert scale (strongly agree $=1$, agree $=2$, neither agree not disagree $=3$, disagree $=4$, strongly disagree $=5$ ). This means that the higher scale shows more egalitarian attitudes in nonreversed items, and fewer egalitarian attitudes in reversed items. We thus reversed the score of the reversed items when calculating so as the higher scale of all items shows more egalitarian attitudes. The total score across the 15 items was calculated, with a higher score indicating a more egalitarian gender role attitude (range from 15 to 75). The reliability coefficient for SESRA-S was reported as 0.91 by Suzuki [27].

\section{Analysis}

We conducted a binomial logistic regression analysis to investigate the factors related to the choice of physics for university entrance exams focusing on the preference for science subjects at junior high school. This analysis was conducted separately for female and male university science graduates who were not professional physicists. The dependent variable of the choice of physics for university entrance exams was regressed on independent variables (age, mathematical stereotype; SESRA-S score; preference and self-efficacy for science subjects in

\footnotetext{
${ }^{8}$ Both nonreversed and reversed items were included in SESRA-S. This is because if we only use nonreversed items (or only reversed items), we cannot eliminate the possibility that the respondents will answer any question in the same way.
} 
TABLE III. Five patterns of the choice of science subjects for university entrance exams.

\begin{tabular}{|c|c|c|c|c|c|c|c|c|}
\hline & \multicolumn{4}{|c|}{ University science graduates } & \multicolumn{4}{|c|}{ Professional physicists } \\
\hline & \multicolumn{2}{|c|}{$\operatorname{Men}(n=547)$} & \multicolumn{2}{|c|}{ Women $(n=554)$} & \multicolumn{2}{|c|}{$\operatorname{Men}(n=419)$} & \multicolumn{2}{|c|}{ Women $(n=71)$} \\
\hline & $N$ & $\%$ & $N$ & $\%$ & $N$ & $\%$ & $n$ & $\%$ \\
\hline (a) One subject of physics & 121 & 22.1 & 41 & 7.4 & 34 & 8.1 & 9 & 12.7 \\
\hline (b) One subject other than physics & 49 & 9.0 & 142 & 25.6 & 4 & 1.0 & 0 & 0.0 \\
\hline (c) More than two subjects including physics & 253 & 46.3 & 141 & 25.5 & 373 & 89.0 & 57 & 80.3 \\
\hline (d) More than two subjects other than physics & 39 & 7.1 & 134 & 24.2 & 2 & 0.5 & 1 & 1.4 \\
\hline (e) Others & 85 & 15.5 & 96 & 17.3 & 6 & 1.4 & 4 & 5.6 \\
\hline
\end{tabular}

elementary, junior high, the first year and second year of high school).

Additionally, we conducted a linear regression model to identify favorite activities and childhood memories of respondents with "high" or "relatively high" preferences for physics at junior high school.

The differences in mathematical stereotype and egalitarian attitude towards gender roles between people who graduated with a degree in science and professional physicists were compared using two-way analysis of variance (ANOVA) for gender and participants' attribute (university science graduates or professional physicists).

The percentage of respondents with high or relatively high preferences and self-efficacy for each science subject was calculated at elementary, junior high, and high school. The percentages for members of the public who graduated with a science degree were then compared with the percentages for professional physicists.

All analyses were conducted using IBM SPSS Statistics 25 software. The level for statistical significance was set at 0.05 .

\section{RESULTS}

\section{A. Pattern of the choice of science subjects for university entrance exams}

A significant difference was found between the choice of science subjects and gender in university science graduates, but not in professional physicists (professional physicist, Fisher's exact test, $p=0.06$; public, chi-squared test, $X^{2}=169.4, \mathrm{df}=4, p<0.01$, Table III). Post hoc residual analysis revealed that males with a science degree significantly chose "(a) one subject of physics" and "(c) more than two subjects including physics." Females with a science degree significantly chose "(b) one subject other than physics" and "(d) more than two subjects other than physics." There was no significant difference in "(e) others" [absolute value of significant difference, (a) 7.0, (b) 7.3, (c) 7.2, (d) 7.8, (e) 0.8].

This finding suggests that females who graduated with science degrees less often chose physics than males who graduated with science degrees. The percentage for "unselected physics" was calculated at $2.9 \%(n=12)$ in male professional physicists, $7.0 \%(n=5)$ in female professional physicists, $31.6 \%$ male university science graduates $(n=173)$, and $67.1 \%(n=372)$ in female university science graduates.

\section{B. Factors related to the choice of physics for university science graduates}

We regressed the dependent variable of the choice of physics for university entrance exams ("unselected physics" was the baseline) on the independent variables of age, mathematical stereotype, preference, and self-efficacy for all science subjects ("low" was the baseline) from elementary school to high school, and the SESRA-S scores. This analysis was conducted only for the group who graduated with a science degree and did not include professional physicists. Many Japanese students choose science or humanities courses at the end of first year of high school. We therefore tested three models: elementary school (model 1), junior high school (model 2), and first year of high school (model 3).

\section{Female university science graduates}

In model 1 , only the coefficient of age was positively significant $(p=0.047$, Table IV). The coefficients of preference and self-efficacy in math and science in elementary school were not statistically significant, suggesting that the preference and self-efficacy in elementary school were not related to the choice of physics.

In model 2 , the high preference $(p<0.001)$ and the relatively high preference $(p=0.003)$ for physics at junior high school were positively significant. The high preference for biology was negatively significant $(p=0.013)$. These results suggest that women who preferred physics or who disliked biology at junior high school chose physics.

In model 3 , the high preference $(p=0.007)$ and the relatively high preference $(p=0.004)$ for physics were positively significant and the high and relatively high preferences for biology were negatively significant (high, $p=0.044$; relatively high, $p=0.09$ ) at the first year of high school. 


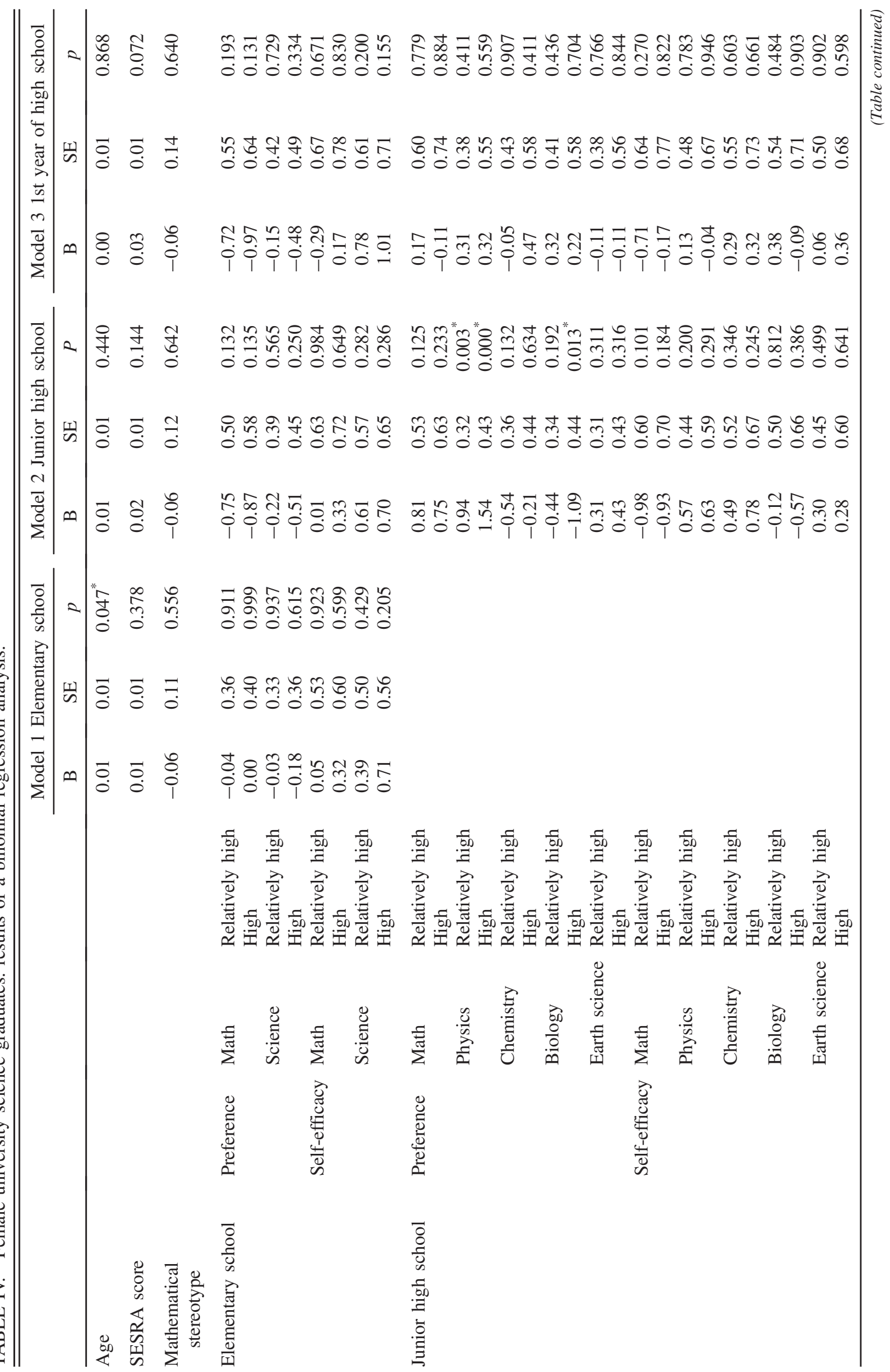




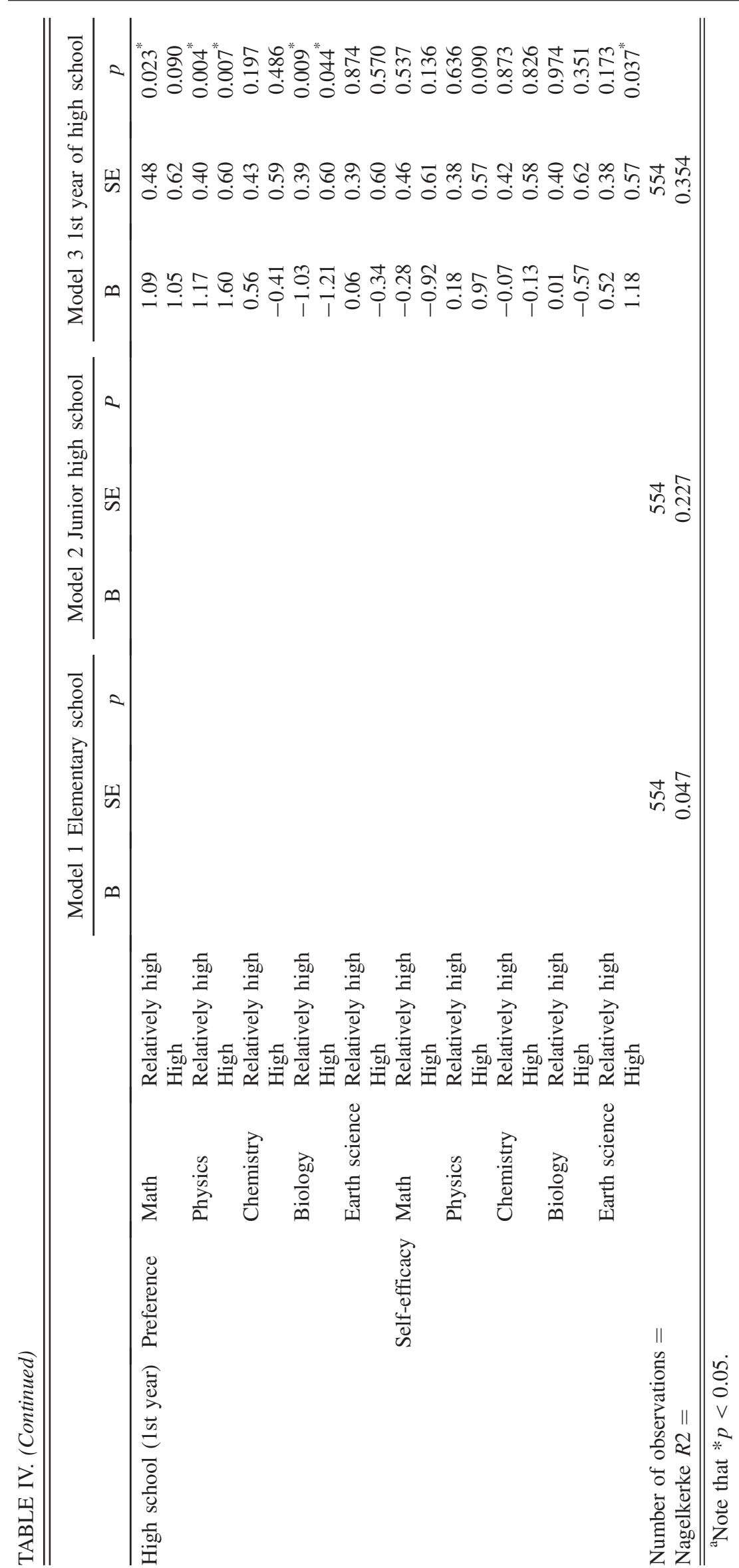




\section{Male university science graduates}

In model 1 , the coefficient of age was statistically significant $(p=0.011$, Table V), suggesting that old men chose physics more often than young men. The "high" preference for math at elementary school was positively significant $(p=0.015)$, meaning that men who preferred math at elementary school chose physics.

In model 2 , the high preference $(p<0.001)$ and the relatively high $(p=0.012)$ preferences for physics at junior high school were positively significant, suggesting that men who preferred physics at junior high school chose physics.

In model 3 , the high preference $(p=0.003)$ and the relatively high $(p=0.003)$ preferences for physics at the first year of high school were positively significant.

\section{Favorite activities and memories related to the preference for physics at junior high school in university science graduates}

A statistical description is summarized in S_Table 2 and S_Table 3 of the Supplemental Material [21]. We conducted a linear regression analysis to investigate the relationship between activities and memories and the preference for physics at junior high school. The dependent variables of the total of the high and "relatively high" preferences for physics at junior high school (low was the baseline) were regressed on independent variables for all favorite activities and memories in elementary and junior high school.

\section{Female university science graduates}

Among the 59 items for activities and memories, eight were significantly related. The coefficients of three items at elementary school were significantly positive: "I liked reading novels or history books (Q1-5)" $(B=0.22, \mathrm{SE}=0.10$, $p=0.022)$, "I liked solving difficult math problems (Q1$14)$ " $(B=0.35, \mathrm{SE}=0.10, p<0.001)$, and "I liked science museums, planetarium, or other museums (Q1-23)" $(B=0.25, \mathrm{SE}=0.12, p=0.048)$ at elementary school.

As well, the coefficients of three items at junior high school were also significantly positive: "I liked science magazines, science articles, science TV shows, Internet science videos, etc. (Q2-8)" $(B=0.26, \quad \mathrm{SE}=0.12$, $p=0.033$ ), "I thought that learning physics would be useful when I entered society in the future (Q2-26)" $(B=0.70, \mathrm{SE}=0.18, p<0.001)$ and "I thought that learning mathematics would be useful when I entered society in the future (Q2-30)" $(B=0.29, \mathrm{SE}=0.133$, $p=0.029)$ at junior high school.

On the contrary, the coefficients of two items were negatively significant at elementary and junior high school: "I liked using the computer (Q1-22)" $(B=-0.52$, $\mathrm{SE}=0.22, p=0.020$ ) at elementary school and "I liked reading novels or history books (Q2-5)" $(B=-0.33$, $\mathrm{SE}=0.10, p<0.001)$ at junior high school.

\section{Male university science graduates}

Three items were significantly related to the preference for physics at elementary and junior high school. The coefficient of the item "I like playing outside (Q1-1)" in elementary school was positively significant $(B=0.08$, $\mathrm{SE}=0.04, p=0.045)$ in elementary school.

The items "I was interested or participated in the International Biology Olympics (Q2-18)" $(B=-0.44$, $\mathrm{SE}=0.22, p=0.049)$ and "I took care of animals or plants (Q2-24)" $(B=-0.16, \mathrm{SE}=0.07, p=0.022)$ at junior high school were negatively significant, suggesting that men who engaged in these biology-related activities were unlikely to show a preference for physics at junior high school.

\section{Mathematical stereotype between professional physicists and university science graduates}

The mean scale for mathematical stereotype was lower in professional physicist than for those who graduated with university science degrees: (mean $\pm \mathrm{SD}$, professional physicist, total $=4.3 \pm 1.1$, men $=4.2 \pm 1.1$, women $=4.4 \pm 1.0$; public, $\quad$ total $=3.6 \pm 1.0, \quad$ men $=3.4 \pm 1.0, \quad$ women $=$ $3.8 \pm 1.0)$. A two-way ANOVA revealed that the main effect of participants' attributes was significant $(F=157.96$, $\mathrm{df}=1, p<0.001)$. The main effect of gender $(F=1.43$, $\mathrm{df}=1, p=0.233)$ and the interaction $(F=1.20, \mathrm{df}=1$, $p=0.273$ ) were not significant, suggesting that professional physicists have a lower belief in mathematical stereotypes than university science graduates.

\section{E. SESRA-S score between professional physicists and university science graduates}

The mean SESRA-S score was higher for professional physicists than for those who graduated with science degrees: $($ mean $\pm \mathrm{SD}$, professional physicist, total $=$ $62.5 \pm 8.2$, men $=61.7 \pm 8.2$, women $=67.0 \pm 6.3$; public, $\quad$ total $=52.3 \pm 9.7, \quad$ men $=49.7 \pm 8.8, \quad$ women $=$ $54.8 \pm 10.0)$. A two-way ANOVA revealed that the main effect of gender $(F=6.87, \mathrm{df}=1, p=0.01)$ and the participants' attributes $(F=538.31, \mathrm{df}=1, p<0.001)$ were both significant, but the interaction was not significant $(F=0.05, \mathrm{df}=1, p=0.03)$. This suggests that female professional physicists have a higher egalitarian attitude than those in the other group.

\section{F. Preferences and self-efficacy of physics between professional physicists and university science graduates}

The female university science graduates tended to lose their preference for physics at junior high school. Both male and female professional physicists showed a "high" or "relatively high" preference for physics from elementary school through to high school. The percentage of preferences for physics in female science graduates fell sharply from elementary (82.9\%) to junior high school 


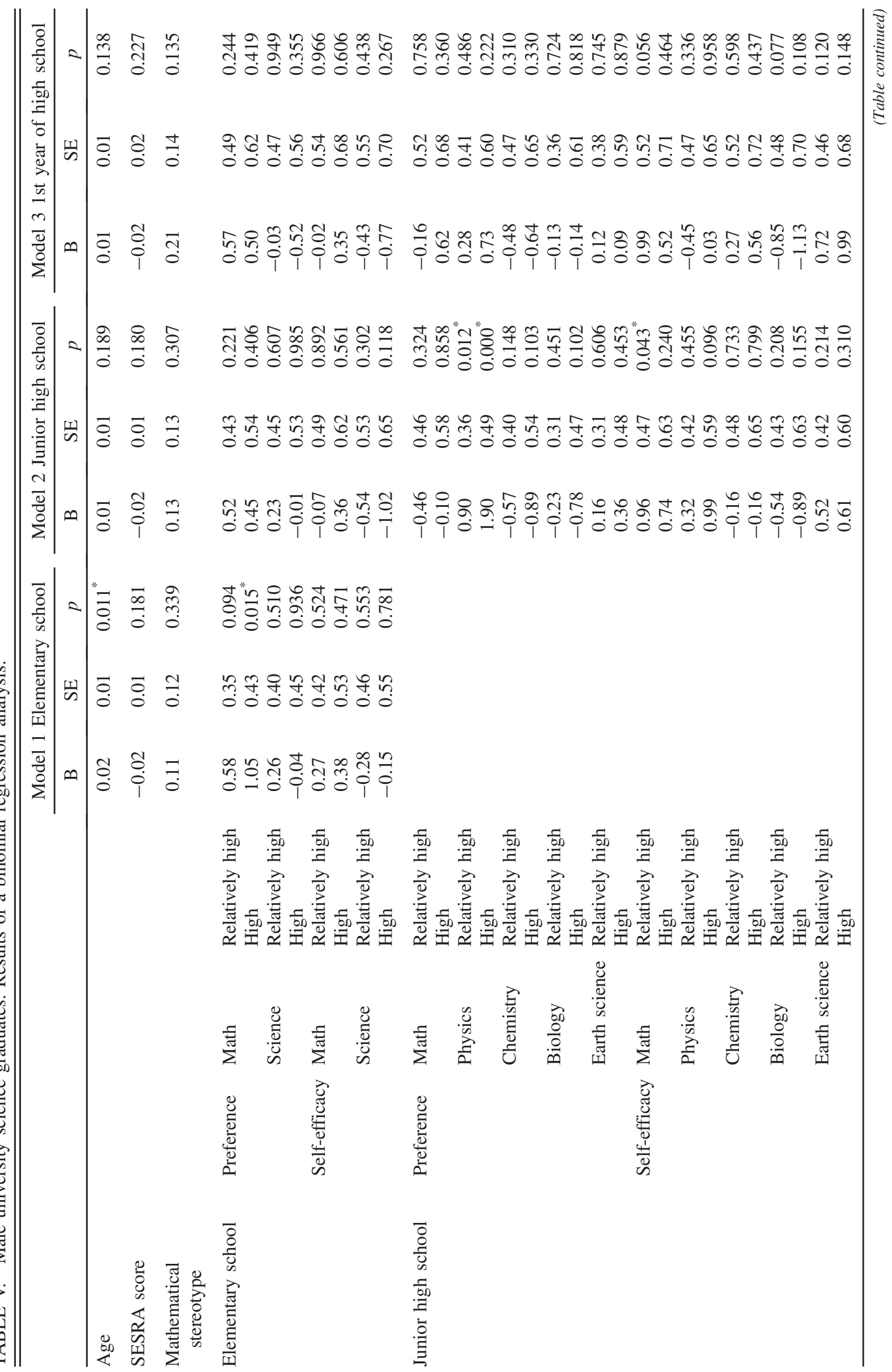




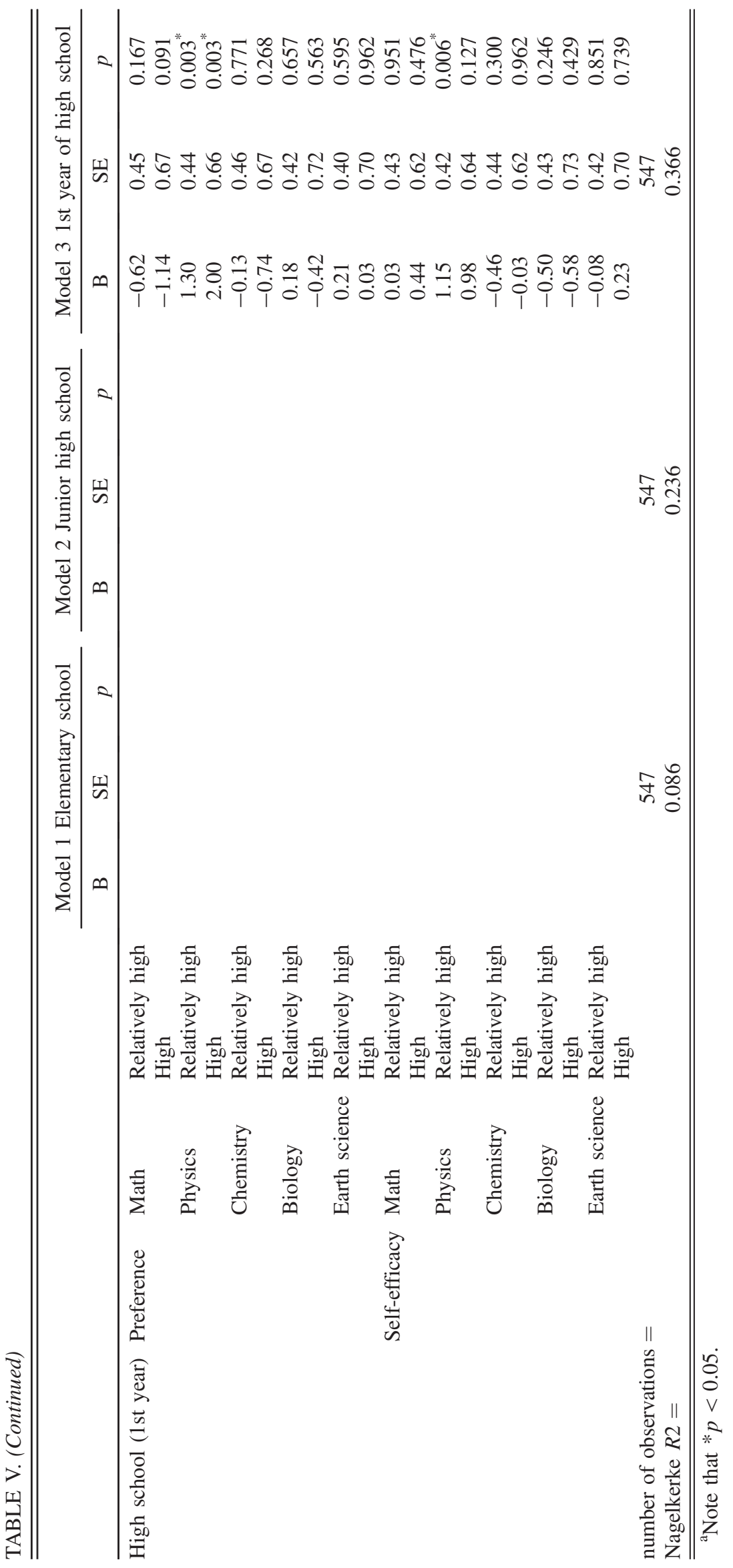


(a) preference

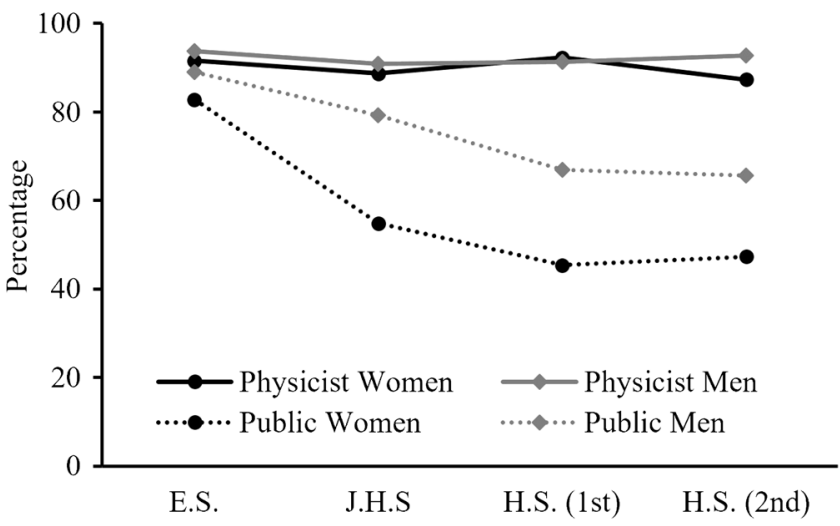

(b) self-efficacy

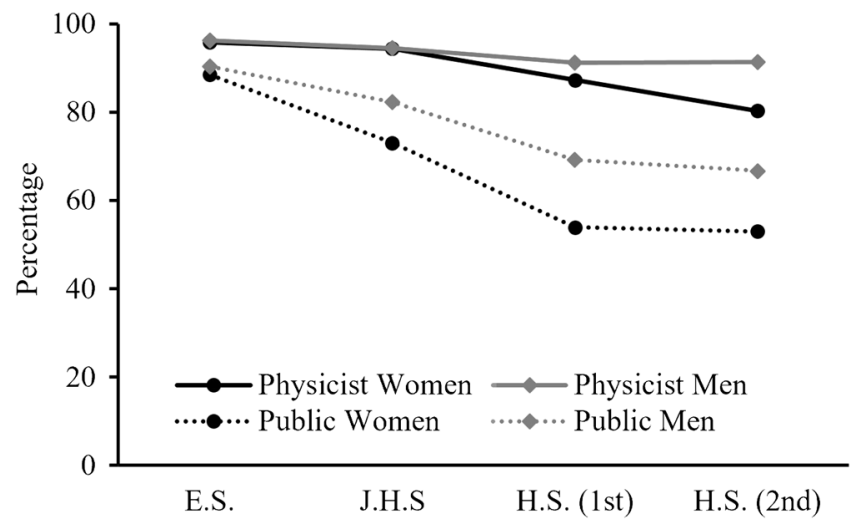

FIG. 1. Percentage of preferences (a) and self-efficacy (b) for physics from elementary school to the second year of high school. The numbers shown are the percentage of the sum of like and probably like in the total of like, probably like, dislike, and probably dislike (a), and the percentage of the sum of I can perform and I probably can perform in the total of I can perform, I probably can perform, I can't perform, and I probably can't perform (b). E.S. = elementary school, J.H.S. = junior(1st) = first high school, H.S. year of high school, H.S. (2nd) $=$ second year of high school.

[54.9\%, Fig. 1(a)]. Similarly, female university science graduates tended to lose their "high" or "relatively high" self-efficacy from junior high (73.1\%) to the first year of high school [53.9\%, Fig. 1(b)]. See S_Figure 4 of the Supplemental Material [21] for the results of other science subjects.

\section{FINDINGS}

- RQ1: We found that the preference for physics at junior high school and the first year of high school were positively related to the choice of physics for university entrance exams in both female and male university science graduates (Tables IV and V). The preference for biology at junior high school and the first year of high school were negatively related to the choice of physics only for female university science graduates (Table IV).

- RQ2: Male university science graduates who liked playing outside at elementary school were likely to prefer physics at junior high school. On the other hand, female university science graduates who liked reading novels or history books, solving difficult math problems, and liked science museums, planetarium, or other museums at elementary school were likely to prefer physics at junior high school. Female university science graduates who, at junior high school, thought that learning physics and mathematics would be useful for the future also preferred physics at junior high school.

- RQ3: Professional physicists, especially women, had a lower mathematical stereotype than male and female university science graduates. Professional physicists had a higher egalitarian attitude for gender roles than university science graduates. Professional physicists had a stable preference for physics from elementary school through to high school, but female university science graduates had a lower preference for physics at junior high school.

\section{DISCUSSION}

In this study, we quantitatively investigated the factors contributing girls' choice of physics for university entrance exams in Japan. We found that the preference for physics at junior high school (model 2; Tables IV and V) or high school (model 3; Tables IV and V) were positively related to the choice of physics for university entrance exams in university science graduates. Both women and men in this group were unlikely to choose physics if they disliked physics at junior high school or high school. Once students dislike physics, it probably means that they are less likely to choose physics as a subject for university entrance exams. This demonstrates that some effort to prevent both junior high school and high school students from disliking physics would be needed to increase future choices for physics.

We found that girls' preference for biology at junior high school (model 2; Table IV) or high school (model 3; Table IV) was also negatively related to the choice of physics. This finding indicates that girls who preferred biology were unlikely to choose physics. The percentage of female Japanese first-year university students was lower in physics (16\%) than biology (38\%), in 2018 [1], demonstrating that women tend to choose biology among the science fields. In Japanese high schools, many students in science courses often choose physics or biology in addition to chemistry. There might be an environment where girls are encouraged to choose biology instead of physics if the girls preferred biology. Preparing an environment in which they can learn both biology and physics may keep their interests in physics besides biology. 
Our results also indicate that female university science graduates abruptly lost their preference for physics in junior high school. This result supports the previous finding that Japanese girls lose their interest in science at junior high school [4]. On the other hand, the percentage of selfefficacy for physics in female university science graduates was higher than preference for physics at junior high school. We did not investigate the causal relationship between the two, but it suggests that the level of preference does not equal to the level of self-efficacy at junior high school, especially for girls. Some studies have reported that the preference for physics differs depending on the areas of physics [30,31]. Among Israeli students, both male and female junior high school students, showed an interest in the study of physics for astronomy and astrophysics, such as "weightless in space" and "black holes" [30]. Other areas of study, such as electricity, energy, forces, and mathematics were perceived as boring by secondary school students in the UK. It is also reported that girls felt physics was boring; they disliked certain areas of study [30]. In Japan, girls showed low interest in "electric currents" and "electric currents and magnetic fields" [4]. These results suggest that students in Japan and in other countries tend to dislike physics in junior high school, but it is not clear how gender affects the preference for some areas of study in physics.

To reduce the number of junior high school girls who dislike physics, a new educational method may be required. One study shows that the method of teaching physics is important for girls. The "cognitively activating method" is known to encourage students to learn physics. Teachers first give a problem to students that cannot be solved with the students' existing knowledge. After the students experience the inability to solve the problem, teachers relate the underlying concept or encourage students to solve different examples, before giving them the formula. This method is reportedly useful for girls with above-average intelligence in secondary school [32]. The behavioral mechanism when girls lose interest in physics is unclear in Japan. Gender Equality Bureau Cabinet Office has provided information on STEM for junior-high-school girls as an initiative Rikōchallenge [2], but it has not been sufficiently tested to be effective what information and when to give. Not only quantitative but also qualitative study is required to examine whether women who went on to physics participated in these initiatives and what information stimulated them while they were junior high school students.

We found that some childhood experiences in elementary and junior high school were significantly related to the preference for physics at junior high school. Male university science graduates who liked playing outside at elementary school preferred physics at junior high school. Their interest in physics might be stimulated through playing outside, but the behavioral mechanism was not revealed in this study. On the other hand, women who graduated with science degrees and liked science magazines, science articles, science TV shows, Internet science videos, etc. and liked science museums, planetarium, or other museums at elementary school showed a preference for physics at junior high school. This finding suggests that the educational environment that parents provided for their daughters at elementary school and junior high school was important for stimulating their daughters' interest in physics. Providing science media materials and going to science museums would be good strategies to develop girls' interest in physics. Our results indicate that there would be at least two opportunities for encouraging girls' interest in physics: at junior high school and at high school. In addition, the preference for physics was influenced by various childhood activities more in girls than in boys at junior high school and high school. Even if a girl dislikes physics at junior high school, she may prefer physics at high school due to experiences outside school. Additionally, women who graduated with science degrees who thought, at junior high school, that learning physics and mathematics would be useful for the future were likely to prefer physics at junior high school. This indicates that girls who recognized the benefit of learning physics and mathematics at early ages could keep their motivations for physics. It may be necessary to encourage parents to give their daughters a variety of experiences in their childhood for future choice of physics.

The SESRA-S score was higher for professional physicists than members of the public who graduated with science degrees. Educational attainment might explain the difference, as about $80 \%$ of professional physicists graduated from doctoral courses, but only $4 \%$ of the university science graduates did. The higher the educational attainment, the more likely the person is to have higher gender equal attitude. Especially, the SESRS-S score was higher in female professional physicists. They might be sensitive for the gender equality, as they produce same results as men in a male-dominated environment. But in this study, it was not clear whether the SESRA-S scores for the professional physicists were innately higher or became higher as they developed.

Similarly, the mathematical stereotype was lower for professional physicists compared with university science graduates. Professional physicists might recognize, through their science careers, that mathematical skills are not different between female and male scientists. Initiatives that reduce the mathematical stereotype could be one role for scientists in society. Future studies will be required to investigate the mechanism for changing stereotypical attitudes.

There were some limitations to this study. First, with professional physicists, we collected 495 responses from professional scientists. There were 15981 JPS members in March 2019 (personal communication, January 22, 2020). Therefore, the recovery rate is presumed to be about $3.1 \%$ if all members were registered for the mailing list. We cannot calculate the exact recovery rate for our questionnaire, as 
the exact number of mailing list registrants is unclear. There is a possibility that only physicists who have relatively high levels of egalitarian attitudes towards gender roles responded to our questionnaire.

Second, with those who graduated from science departments or faculties, we expected that the respondents did not include professional physicists. As the respondents who graduated from physics department at universities were only 3.4\% $(n=37)$ (Supplemental Material [21]), we thus considered that the possibility would be low. However, we cannot deny this possibility, as we did not ask whether they were a professional physicist or not.

Third, we should be careful that we collected almost the same percentage of samples from women $(n=554$, $50.3 \%)$ and men $(n=547,497 \%)$. This means that our sample is not the representative of those who graduated from science-related department or faculty. The actual percentage of undergraduate university students in science-related faculties is higher for men $(38.3 \%)$ than for women (27.2\%) in 2019 [33].

Fourth, our survey was based on retrospective design. Retrospective survey has generally a disadvantage about data reliability as the respondent may answer with a wrong memory and have recall bias [34]. Retrospective survey is suitable to roughly identify the factors as a first step, but long-term follow-up study for the same respondents would be better to catch the trend more accurately.

In Japan, there are insufficient data to know what students' attitudes toward physics by gender (not limited to women and men). For example, the National Assessment of Academic Ability, conducted annually by MEXT for sixth- and ninth-grade students nationwide, is not a followup survey. In addition, while the questionnaire captures interest and attitudes toward science in general, it does not capture those in each field of science, such as physics, chemistry, biology, and earth science. There is an urgent need to establish a system to obtain more detailed data from students on a regular basis and to identify problems more clearly at a policy level. It was also suggested that the increase in the number of female students studying physics would be related to noncognitive skills in physics (ex., intellectual interest, academic confidence, motivation, selfconcept, attitudes, etc.) that cannot be measured by academic tests. It would be important in increasing the number of female students majoring in physics to strengthen the research in this area and to develop policies to intervene to noncognitive skills in physics, especially for junior high school students. Furthermore, with the change of the government education guideline in Japan, active learning is being requiring more instead of one-way teaching of knowledge. STEAM education is to be given more emphasis in 6th the Science, Technology and Innovation Basic Plan from 2021. In line with these education policy trend, it is necessary to develop and implement educational programs that are more inquisitive and interesting in physics at junior high and high schools.

\section{CONCLUSION}

We investigated the factors related to the choice of physics for university entrance exams in Japan. We found that, among female university science graduates, the preference for physics and the disfavor for biology at junior high school and high school were significantly related to their later choice of physics as a subject for university entrance examination. Our results suggest that initiatives that prevent junior high school or high school students from developing a dislike for physics may be important to increase their future selection of advanced physics at university.

\section{ACKNOWLEDGMENTS}

This work was funded by a Japan Science and Technology Agency (JST)-RISTEX (Research Institute of Science and Technology for Society) research program (number JPMJRX17B3) and supported by the World Premier International Research Center Initiative (WPI), MEXT, Japan.
[1] Ministry of Education, Culture, Sports, Science and Technology (MEXT), Gakkō Kihon Chōsa, https:// www.e-stat.go.jp/stat-search/database?page $=1 \&$ toukei $=$ $00400001 \&$ tstat $=000001011528$ (2018).

[2] Gender Equality Bureau Cabinet Office, Rikō-challenge, http://www.gender.go.jp/c-challenge/ (n.d.).

[3] National Institute for Educational Policy Research, Heisei 30 nendo zenkoku gakuryoku gakushū jōkyōchōsa no kekka, https://www.nier.go.jp/18chousakekkahoukoku/ 18summary.pdf (n.d.).
[4] Y. Harada, K. Sakamoto, and M. Suzuki, When and why have lower secondary school students disliked science learning? A basic study based on expectancy-value theory, J. Nat. Resour. Life Sci. Educ. 58, 319 (2019).

[5] Ministry of Education, Culture, Sports, Science and Technology (MEXT), Gakushu Shidō Yōryō ikiru chikara, http://www.mext.go.jp/a_menu/shotou/new-cs/youryou/ 1304427.htm (n.d.).

[6] Science Council of Japan, Korekarano rikakyōikuno arikata, http://www.scj.go.jp/ja/info/kohyo/pdf/kohyo-23t224-1.pdf (2016). 
[7] Center for Promotion of Science Education, Japan Science and Technology Agency, Heisei 20 nendo kōtogakkō rikakyōin jittaichōsa hōkokusho, http://www.jst.go.jp/ cpse/risushien/highschool/cpse_report_009.pdf (2010).

[8] National Institute for Educational Policy Research, Rikeibunkei Shinro Sentaku ni kakawaru Ishiki Chōsa, https:// www.nier.go.jp/kaihatsu/pdf/zokuseichi-report.pdf (2012).

[9] The Japan Inter-Society Liaison Association Committee for Promoting Equal Participation of Men and Women in Science and Engineering, 2017 nen Gakkyōkai Jyosei Hiritsu Chōsa, https://www.djrenrakukai.org/doc_pdf/ 2017_ratio/2017_ratio_table.pdf (n.d.).

[10] M. Nojiri, Butsuri gakkai ni okeru danjyo kyōdō sankaku mondai, Butsuri tanko 73, 331 (2018).

[11] L. E. Kost, S. J. Pollock, and N. D. Finkelstein, Characterizing the gender gap in introductory physics, Phys. Rev. ST Phys. Educ. Res. 5, 010101 (2009).

[12] S. Cheryan, S. A. Ziegler, A. K. Montoya, and L. Jiang, Why are some STEM fields more gender balanced than others?, Psychol. Bull. 143, 1 (2017).

[13] Y. Ikkatai, A. Inoue, A. Minamizaki, K. Kano, E. McKay, and H.M. Yokoyama, Masculinity in the public image of physics and mathematics: A new model comparing Japan and England, Publ. Understand. Sci., https://doi.org/ 10.1177/09636625211002375 (2021).

[14] M. M. Bleeker and J. E. JacobsAchievement in math and science: Do mothers' beliefs matter 12 years later?, J. Educ. Psychol. 96, 97 (2004).

[15] Y. Morinagaand K. Sakata, Y. Furukawa, and K. Fukudome, Mathematics motivation and gender stereotypes of junior and senior high school girls, Jpn. J. Educ. Psychol. 65, 3 (2017).

[16] Benesse Corporation, Shinro sentaku ni kansuru furukaeri chōsa, https://berd.benesse.jp/koutou/research/detail1.php? $\mathrm{id}=3170$ (2006).

[17] Libertas Consulting Co., Ltd., Joshikōseira no rikōkei shinrō sentaku shien ni muketa seitora no ishiki ni kansuru chōsakenkyū, http://www.gender.go.jp/research/kenkyu/ pdf/girls-course_h29.pdf (2018).

[18] A. Dicke, N. Safavian, and J. S. EcclesTraditional gender role beliefs and career attainment in STEM: A gendered story?, Front. Psychol. 10, 1053 (2019).

[19] World Economic Forum, Global Gender Gap Report 2020, https://jp.weforum.org/reports/gender-gap-2020-report100-years-pay-equality.

[20] Y. Ikkatai, A. Inoue, K. Kano, A. Minamizaki, E. McKay, and H.M. Yokoyama, Parental egalitarian attitudes towards gender roles affect agreement on girls taking STEM fields at university in Japan, Int. J. Sci. 41, 16 (2019).
[21] See Supplemental Material at http://link.aps.org/ supplemental/10.1103/PhysRevPhysEducRes.17.010141.

[22] Ministry of Education, Culture, Sports, Science and Technology (MEXT), Gakkō Kihon Chōsa, https:// www.e-stat.go.jp/stat-search/database?page $=1 \&$ toukei $=$ $00400001 \&$ tstat $=000001011528$ (n.d.).

[23] National Institute of Science and Technology Policy (NISTEP), 1st report of 'Japan Doctoral Human Resource Profiling' FY2012 doctoral graduates cohort, NISTEP Report 165 (2015).

[24] Physical Society of Japan (JPS), https://www.jps.or.jp/.

[25] Statistics Bureau of Japan, Rōdōryokuchōsa kihonshukei 2020 nen (reiwa 2 nen) 12 gatsubun kekka, https://www.stat .go.jp/data/roudou/sokuhou/tsuki/index.html (2021).

[26] M. Hosotsubo, K. Kano, and A. Okamura, Public attitudes to science and technology: Effects of child/student period, NISTEP Res. Mater. 265 (2017).

[27] A. Suzuki, Construction of a short-form of the scale of egalitarian sex role attitudes (SESRA-S), Jpn. J. Psychol. 65, 1 (1994).

[28] M. Ui, Jendā Seiyakuwari, in Shinri Sokutei Syakudoshu II, edited by H. Hori and M. Yamamoto (Saiensu-Sha Co., Ltd., Tokyo, 2001), pp. 138-172.

[29] M. Uji, M. Shono, N. Shikai, H. Hiramura, and T. Kitamura, Egalitarian sex role attitudesamong Japanese human service professionals: Confirmatory factor analytic study, Psychiatry Clin. Neurosci. 60, 3 (2006).

[30] R. Trumper, Factors affecting junior high school students' interest in physics, J. Sci. Educ. Technol. 15, 47 (2006).

[31] C. Williams, M. Stanisstreet, K. Spall, E. Boyes, and D. Dickson, Why aren't secondary students interested in physics?, Phys. Educ. 38, 4 (2003).

[32] S. I. Hofer, R. Schumacher, H. Rubin, and E. Stern, Enhancing physics learning with cognitively activating instruction: A quasi-experimental classroom intervention study, J. Educ. Psychol. 110, 1175 (2018).

[33] Ministry of Education, Culture, Sports, Science and Technology (MEXT), Gakkō Kihon Chōsa, https:// www.e-stat.go.jp/stat-search/database?page $=1 \&$ toukei $=$ $00400001 \&$ tstat $=000001011528$ (2019).

[34] J. Scott and D. Alwin, Retrospective versus prospective measurement of life histories in longitudinal research, in Methods of Life Course Research: Qualitative and Quantitative Approaches, edited by J. Z. Giele and G. H. Elder, Jr. (SAGE Publications, Inc., Thousand Oaks, CA, 1998), pp. 98-127, https://doi.org/10.4135/9781483348919.n5. 